\section{ELEIÇÕES CONSCIENTES E QUOCIENTES DAS ELEIÇÕES*}

Mário Sérgio Demarzo**

"A desgraça dos que não se interessam pela Política é serem governados pelos que se interessam".

(Autor desconhecido.)

"O meu candidato teve mais votos do que o seu e não foi eleito. Como pode?'

Infelizmente, pode sim e, para entender como e quando isso acontece, é preciso conhecer a legislação eleitoral

Nas eleições para o Senado e para os cargos Executivos, o princípio de representação adotado é o princípio majoritário.

Todavia, para a Câmara de Deputados, Assembléia Legislativa e Câmara Municipal é utilizado o princípio proporcional. O preenchimento das cadeiras, nas eleições proporcionais, é feito com base no cálculo do quociente eleitoral e do quociente partidário. Em outras palavras, para conhecer o processo eletivo em matéria de eleição proporcional, é preciso entender o que significa quociente eleitoral e quociente partidário.

Esse assunto é muito pouco abordado não só pela imprensa em geral, como pelos candidatos e partidos, em particular. Está disciplinado pelo Código Eleitoral (Lei n. ${ }^{\circ}$ 4.737/65), na sua Parte Quarta, Título I, Capítulo IV, "Da Representação Proporcional" (artigos 105 a 113) e na chamada "Lei de Eleições" (Lei n. ${ }^{\circ}$ 9.504, de 30.09.97).

Acreditamos que seja do interesse de todos os eleitores a divulgação deste assunto. Os operadores de Direito devem assumir a responsabilidade de contribuir para a erradicação dos analfabetos políticos a que se referia Bertolt Brecht.

* O presente artigo nasceu das discussões dentro do Centro de Pensamento Político, da Uniara, sob a coordenação da Profa. Dra. Inayá Bittencourt e Silva.

** Advogado pelo Centro Universitário de Araraquara - UNIARA; Bacharel e Licenciado em Letras pela Faculdade de Filosofia, Ciências e Letras - Santo André-SP e Economista pela Faculdade de Ciências Econômicas do Sul de Minas - Itajubá-MG
A aquisição plena da cidadania, entendida como exigência democrática, passa, de maneira geral, pela tomada de consciência, em todas as áreas do conhecimento. A discussão de tópicos da legislação eleitoral deve, portanto, fazer parte das nossas preocupações, com o sentido de colaborar para o aperfeiçoamento democrático.

Segundo dados divulgados pelo jornal "AÇÃO" n" 114, de 17.09.98, da ANABB, em 1994, 16,8 milhões de eleitores não votaram, 12,6 milhões votaram em branco e 19,4 milhões anularam os votos para deputado federal.

Mas, o mais inquietante é que dos 45,9 milhões de votos válidos, a impressionante quantidade de 22,6 milhões não elegeu ninguém! Tanto o PFL quanto o PT, naquelas eleições, tiveram cerca de 6 milhões de votos, mas o primeiro elegeu cerca de 90 deputados e o segundo somente 49.

Tentemos, então, percorrer os atalhos da legislação, com a intenção de entender o mecanismo que rege as eleições proporcionais.

\section{O quociente eleitoral}

A primeira providência a tomar é conhecer o significado do quociente eleitoral e proceder ao seu cálculo (art. 106, Código Eleitoral). Para isso, é preciso verificar o total de votos válidos. Não são considerados válidos os votos em branco, nem os nulos, conforme artigo $5^{\circ}$ da Lei 9.504/97.

Esse total deve ser dividido pelo número de vagas em disputa nas eleições. O quociente eleitoral representa o resultado da divisão do número de votos válidos pela quantidade de vagas disponíveis. Por exemplo, se existem 10 vagas para serem preenchidas e o total de votos válidos somar 1.000 .000 de votos, teremos um quociente eleitoral (QE) de 100.000 votos:

\begin{tabular}{|c|c|}
\hline Quaiente eleitoraltetal de votos válidos & $Q E=\frac{1.000000}{10}=100000$ \\
\hline
\end{tabular}

Nesse caso hipotético, um partido (ou coligação), para eleger um deputado, deve conseguir 100.000 votos no mínimo. Se conseguir 99.000 não elege nenhum. Se conseguir, por exemplo, 150.000, continuará com direito a somente um deputado. A questão seguinte é o cálculo do Quociente Partidário.

Registre-se que em caso de haver coligação para a eleição proporcional (que é a que conta no presente caso) ela não precisa, necessariamente, ser idêntica à da eleição majoritária. Por exemplo, nas últimas eleições municipais, em Araraquara, as coligações para prefeito eram diferentes daquelas para vereador.

\section{O quociente partidário}

Veja-se: cada partido (ou coligação) só tem direito a colocar na Câmara o seu quociente partidário, que nada mais é do que o número total de votos 
válidos recebidos pelo partido e dividido pelo quociente eleitoral, desprezada a fração (art. ${ }^{\circ} .107$ do Código Eleitoral).

Por exemplo, digamos que um partido conseguiu, no total, 380.000 votos válidos e que o quociente eleitoral seja 100.000, conforme o exemplo hipotético já referido. $\mathrm{O}$ quociente partidário de tal partido será:

$$
\text { Quociente Partidáritontul de votos válidos recebidos nelo partieg } \frac{380000}{100000}=3
$$

Como não são consideradas as frações, mas somente os inteiros, no caso visto o partido tem direito a eleger os seus três candidatos mais votados (que podem ou não ter atingido 100.000 votos), ficando perdidos 80.000 votos.

\section{Exemplos ilustrativos}

O quociente eleitoral fornece o número mínimo de votos para eleger um deputado. Já o quociente partidário fornece o número de deputados a que cada partido tem direito.

Para verificar como podem ocorrer distorções, examinemos o quadro hipotético abaixo, considerando os partidos A, B, C, D, e os candidatos $\mathbf{1}$ até 13 .

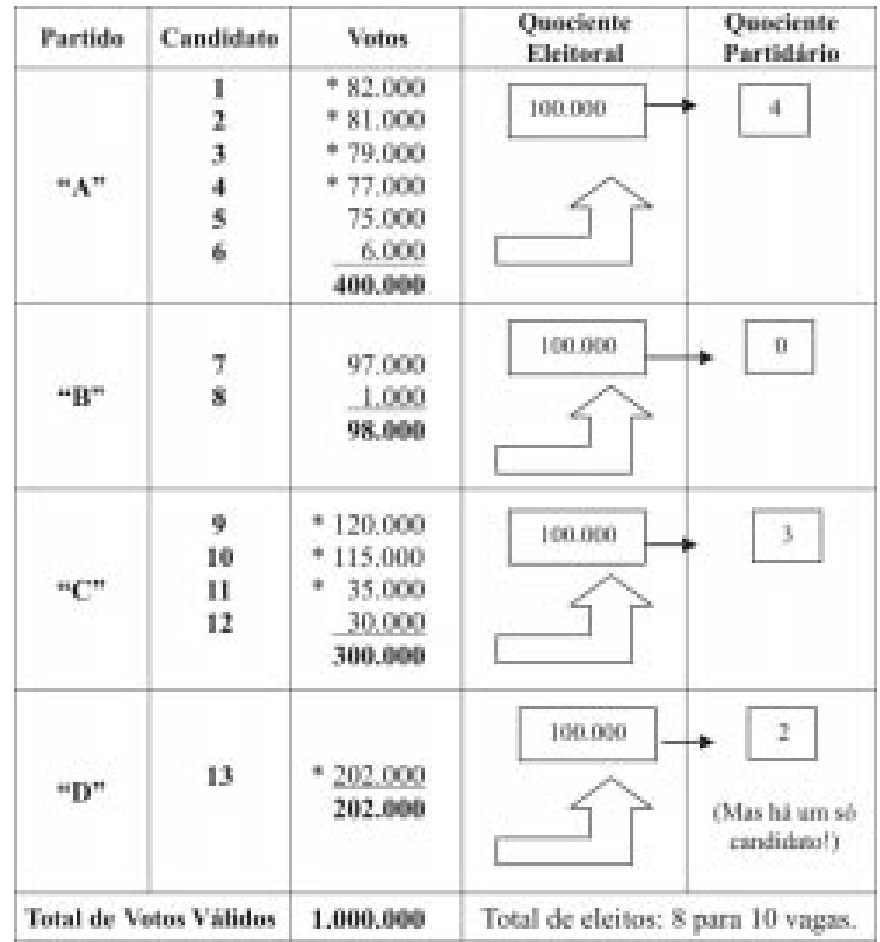

O caso das 2 vagas remanescentes será tratado mais adiante, neste trabalho.
Podemos observar que, em tal hipótese, o candidato mais votado do partido " $\mathrm{B}$ " tem, isoladamente, mais votos do que qualquer candidato do partido " $\mathrm{A}$ ", porém não será eleito, porque seu partido, com 98.000 votos, não atingiu o quociente eleitoral de 100.000, conforme o art. 109, $\S 2^{\circ}$ do Código Eleitoral. Observe-se que o terceiro candidato do partido " $\mathrm{C}$ " tem quase três vezes menos votos do que ele e está eleito! Em compensação, os quatro primeiros do "A" têm suas vagas garantidas. Por outro lado, não é menos irônica a situação dos dois mais votados do partido "C" e o do candidato único do partido "D", quando são comparados com todos os demais candidatos (o "D", inclusive, só não elege mais um candidato porque não o tem).

Tais exemplos nos mostram porque um candidato com menos votos é eleito e o outro, às vezes tendo até mais do que o dobro, não o é

\section{Coligação e vagas remanescentes}

Algumas hipóteses interessantes devem ser examinadas:

- a partir do que diz o citado artigo 107, "in fine", do Código Eleitoral, na determinação do quociente partidário o número de votos a ser considerado é o do partido ou da "coligação de legendas"?

- e o que ocorre quando não são preenchidos todos os lugares em disputa, após a distribuição de vagas a partir dos quocientes eleitoral e partidário (art. ${ }^{\text {. }}$. 109 do Código Eleitoral)?

- se nenhum partido ou coligação atingir o quociente eleitoral, qual é a solução?

No primeiro dos casos retro-mencionados, examinemos a hipótese de que os partidos "B" e "D" estivessem concorrendo em coligação. A soma total de ambos seria de 300.000 (98.000 do partido "B" e 202.000 do partido "D"). Neste caso, dividindo-se o total de votos da coligação pelo quociente eleitoral de 100.000 (conforme o exemplo inicial) o quociente partidário da coligação "B"/"D" atingiria "3" e, assim, todos os candidatos da coligação estariam eleitos, inclusive o menos votado de toda a eleição, o de n. "8", com 1.000 votos!

Por outro lado, pode ser que nem todas as vagas sejam preenchidas, o que é previsto pelo artigo 109 do Código Eleitoral. Aliás, na hipótese que estamos analisando, estariam em disputa 10 vagas e somente foram eleitos 8 candidatos.

A lei diz que se deve tomar o total de votos obtidos pelo partido ou coligação e dividir pelo quociente partidário acrescido de um (art. ${ }^{\circ}$. 109, inciso I, Código Eleitoral). Quem obtiver a melhor média obtém uma vaga a mais. Repete-se o artificio, sendo que o partido ou coligação que leva a nova vaga, carrega o novo quociente partidário para a nova rodada, e assim sucessivamente, até que todas as vagas sejam preenchidas (art. 109, inciso II, mesmo código).

Vejamos o que ocorreria no nosso caso, considerando-se que o partido que não atinge o quociente eleitoral mínimo não entra (art. ${ }^{\circ} .109, \S 2^{\circ}$, Código 
Eleitoral). Além de o partido "B" ficar de fora, o mesmo ocorre com o "D", que tem candidato único. Vão para a disputa os partidos " $\mathrm{A}$ " e "C":

\begin{tabular}{|c|c|c|c|c|}
\hline Partidoo & Total de Votos & QE origginal & QE+1 & Média Obtida \\
\hline${ }^{-A^{*}}$ & 400.000 & 4 & 5 & 80.600 \\
\hline $\mathrm{C}^{-1}$ & 300.000 & 3 & 4 & 75000 \\
\hline
\end{tabular}

Como resultado, a primeira das vagas restantes fica com o partido "A", que obtém a melhor média na nova situação. Todavia, ainda há uma outra vaga a ser preenchida.

Vamos, portanto, para nova rodada, já se considerando o novo quociente eleitoral do "A" (que levou a vaga anterior e, agora, tem 5 eleitos) e repetindo o QP original do partido "C" (que continua somente com 3 eleitos):

\begin{tabular}{|c|c|c|c|c|}
\hline Partide & Total de Votos & QE & QE+1 & Média Obtida \\
\hline $\mathrm{C}^{-}$ & 400.000 & 5 & 6 & 66.666 \\
\hline${ }^{\circ} \mathrm{C} "$ & 300,000 & 3 & 4 & 75,000 \\
\hline
\end{tabular}

Portanto, a última vaga vai para o partido "C" que, desta vez, ficou com a média maior.

Interessante é registrar que, em qualquer caso, quando há empate de votos, será considerado eleito o candidato mais idoso (art.110 do Código Eleitoral).

Finalmente, se nenhum partido (ou coligação) obtiver índice partidário, serão eleitos os mais votados, independentemente de partido ou coligação (art. 111 do Código Eleitoral).

\section{Algumas considerações}

O sistema de eleições proporcionais, aqui tratado, teve sua origem no famoso "pacote de abril", no governo de Ernesto Geisel. Acreditamos que represente, no seu atual funcionamento, um ponto a ser questionado na democracia representativa brasileira. A dificuldade em removê-lo ou mudá-lo tem sido sentida, mormente depois de cada eleição, ao deixar decepcionados os cidadãos que tiveram sua escolha deturpada e que não entendem como ele realmente funciona.

Uma das condições para se fazer uma boa indicação, em tal caso, é, sem dúvida, conhecer a relação de todos os candidatos do partido (ou coligação) e ter informações sobre eles, podendo, assim, fazer a seleção dos melhores. Reconheça-se que é tarefa difícil e, até, quixotesca, tendo em vista, provavelmente, de um lado, o desinteresse da maioria dos eleitores brasileiros e, de outro, certa imprecisão ideológica dos nossos partidos políticos. A transferência de votos para outros candidatos, dentro da legenda ou da coligação, de acordo com o sistema proporcional, traz o risco de o eleitor eleger, indiretamente, um candidato que, de outra forma, não receberia seu voto, frustrando a motivação de optar pela escolha do melhor

O sistema de eleições proporcionais como o brasileiro (é interessante consultar Alexandre de Moraes, "Sistemas eleitorais e regime de governo presidencial", in Revista do Advogado, Ano XXIV, n.79, outubro de 2004, p.720, publicação da AASP) apresenta-se, em nossa opinião, incapaz de expressar com exatidão a vontade política dos cidadãos, devendo merecer atenção na reforma política, cuja realização prática, ao que parece, não tem sido enfrentada convenientemente.

\section{Referências bibliográficas:}

AMARAL, Roberto; CUNHA, Sérgio Sérvulo da. Manual das eleições. 2.ed. São Paulo: Saraiva, 2002.

CONSTITUIÇÃO FEDERAL. Código Eleitoral. Legislação Eleitoral e Política - TSE - Regimento e Resoluções - Barueri: Manole, 2004.

AÇÃO. Jornal da ANABB - Associação Nacional dos Funcionários do Banco do Brasil. Brasília, n. 114, ano XII, 17 set. 1998.

\section{Resumo:}

O objetivo do trabalho é mostrar porque um candidato pode obter maior número de votos, mas a vaga é dada a outro, menos votado.

Nas eleições brasileiras, para o Senado e cargos Executivos, o princípio é o majoritário. Não sendo assim para a Câmara dos Deputados, Assembléia Legislativa e Câmara Municipal, onde é seguido o princípio proporcional. Para entendê-lo é necessário saber o que significam os quocientes eleitoral e o partidário. $\mathrm{O}$ primeiro corresponde à divisão do total de votos válidos pelo número de vagas disponíveis. O segundo é a divisão do total de votos válidos recebidos pelo partido, pelo quociente eleitoral.

São apresentados exemplos práticos, comentando-se o que acontece quando da ocorrência de coligações entre os partidos, bem como quando ocorre o não preenchimento das vagas existentes.

Externa-se o pensamento de que os conceitos comentados e exemplificados devam contribuir para uma melhor discussão do processo e melhoria das condições eleitorais no Brasil.

\section{Palavras-chave:}

Princípio Proporcional, Quociente Eleitoral, Quociente Partidário, Cidadania, Coligação, Vagas Remanescentes. 